\title{
Quantification of human bone microarchitecture damage in press-fit femoral knee implantation using HR-pQCT and digital volume correlation
}

Citation for published version (APA):

Rapagna, S., Berahmani, S., Wyers, C. E., van den Bergh, J. P. W., Reynolds, K. J., Tozzi, G., Janssen, D., \& Perilli, E. (2019). Quantification of human bone microarchitecture damage in press-fit femoral knee implantation using HR-pQCT and digital volume correlation. Journal of the mechanical behavior of biomedical materials, 97, 278-287. https://doi.org/10.1016/j.jmbbm.2019.04.054

Document status and date:

Published: 01/09/2019

DOI:

10.1016/j.jmbbm.2019.04.054

Document Version:

Publisher's PDF, also known as Version of record

Document license:

Taverne

Please check the document version of this publication:

- A submitted manuscript is the version of the article upon submission and before peer-review. There can be important differences between the submitted version and the official published version of record.

People interested in the research are advised to contact the author for the final version of the publication, or visit the DOI to the publisher's website.

- The final author version and the galley proof are versions of the publication after peer review.

- The final published version features the final layout of the paper including the volume, issue and page numbers.

Link to publication

\footnotetext{
General rights rights.

- You may freely distribute the URL identifying the publication in the public portal. please follow below link for the End User Agreement:

www.umlib.nl/taverne-license

Take down policy

If you believe that this document breaches copyright please contact us at:

repository@maastrichtuniversity.nl

providing details and we will investigate your claim.
}

Copyright and moral rights for the publications made accessible in the public portal are retained by the authors and/or other copyright owners and it is a condition of accessing publications that users recognise and abide by the legal requirements associated with these

- Users may download and print one copy of any publication from the public portal for the purpose of private study or research.

- You may not further distribute the material or use it for any profit-making activity or commercial gain

If the publication is distributed under the terms of Article $25 \mathrm{fa}$ of the Dutch Copyright Act, indicated by the "Taverne" license above, 


\title{
Quantification of human bone microarchitecture damage in press-fit femoral knee implantation using HR-pQCT and digital volume correlation
}

\author{
Sophie Rapagna ${ }^{\mathrm{a}}$, Sanaz Berahmani ${ }^{\mathrm{b}}$, Caroline E. Wyers ${ }^{\mathrm{c}, \mathrm{d}}$, Joop P.W. van den Bergh ${ }^{\mathrm{c}, \mathrm{d}}$, \\ Karen J. Reynolds ${ }^{\mathrm{a}}$, Gianluca Tozzi ${ }^{\mathrm{e}}$, Dennis Janssen ${ }^{\mathrm{b}}$, Egon Perilli ${ }^{\mathrm{a}, *}$ \\ ${ }^{a}$ Medical Device Research Institute, College of Science and Engineering, Flinders University, Adelaide, South Australia, Australia \\ ${ }^{\mathrm{b}}$ Radboud University Medical Center, Radboud Institute for Health Sciences, Orthopaedic Research Lab., Nijmegen, the Netherlands \\ ${ }^{\mathrm{c}}$ Department of Internal Medicine, VieCuri Medical Centre, Venlo, the Netherlands \\ ${ }^{\mathrm{d}}$ NUTRIM School of Nutrition and Translational Research in Metabolism, Maastricht University Medical Centre, Maastricht, the Netherlands \\ ${ }^{\mathrm{e}}$ Zeiss Global Centre, School of Engineering, University of Portsmouth, UK
}

A R T I C L E I N F O

\section{Keywords:}

Press-fit implantation

Uncemented total knee replacement

Trabecular bone deformation

HR-pQCT

Digital volume correlation

\begin{abstract}
A B S T R A C T
Primary press-fit fixation of femoral knee prostheses is obtained thanks to the inside dimensions of the implant being undersized with respect to the bone cuts created intra-operatively, dictated by a press-fit specified by the implant design. However, during prostheses press-fit implantation, high compressive and shear stresses at the implant-bone interface are generated, which causes permanent bone damage. The extent of this damage is unknown, but it may influence the implant stability and be a contributing factor to aseptic loosening, a main cause of revisions for knee arthroplasty. The aim of this ex-vivo study was to quantify, using high-resolution peripheral quantitative computed tomography (HR-pQCT) imaging and Digital Volume Correlation (DVC), permanent bone deformation due to press-fit femoral knee implantation of a commonly used implant. Six human cadaveric distal femora were resected and imaged with HR-pQCT (60.7 $\mu \mathrm{m} /$ voxel, isotropic). Femurs were fitted with cementless femoral knee implants (Sigma PFC) and rescanned after implant removal. For each femur, permanent deformation was examined in the anterior, posterior-medial and posterior-lateral condyles for volumes of interest (VOIs) of $10 \mathrm{~mm}$ depth. The bone volume fraction (BV/TV) for the VOIs in pre- and postimplantation images was calculated, at increasing depth from the bone surface. DVC was applied on the VOIs pre- and post-implantation, to assess trabecular bone displacements and plastically accumulated strains. The "BV/TV $\mathrm{post}_{\mathrm{BV}} / \mathrm{TV}$ pre ratio vs. depth" showed, consistently among the six femurs, three consecutive points of interest at increasing bone depth, indicating: bone removal (ratio $<100 \%$ ), compaction (ratio $>100 \%$ ) and no changes (ratio $=100 \%$ ). Accordingly, the trabecular bone displacement computed by DVC suggested bone compaction up to $2.6 \pm 0.8 \mathrm{~mm}$ in depth, with peak third principal strains of $-162,100 \pm 55,000 \mu \varepsilon$ (mean absolute error: $1,000-2,000 \mu \varepsilon$, SD: $200-500 \mu \varepsilon$ ), well above the yield strain of bone $(7,000-10,000 \mu \varepsilon)$. Combining 3D-imaging, at spatial resolutions obtainable with clinical HR-pQCT, and DVC, determines the extent of plastic deformation and accumulated compressive strains occurring within the bone due to femoral press-fit implantation. The methods and data presented can be used to compare different implants, implant surface coatings and press-fit values. These can also be used to advance and validate computational models by providing information about the bone-implant interface obtained experimentally. Future studies using these methods can assist in determining the influence of bone damage on implant stability and the subsequent osseointegration.
\end{abstract}

\section{Introduction}

The primary objective of press-fit fixation is to provide initial stability, reduce micro-motions at the implant-bone interface and promote long term fixation via osseointegration (Kienapfel et al., 1999). It is important that the implant is properly fitted to allow load transfer and implant stability to enable osseointegration, with micromotions up to $30 \mu \mathrm{m}$ being beneficial for bone growth, whereas motions over $150 \mu \mathrm{m}$ prevent effective osseointegration (Apostu et al., 2018; Jemat et al., 2015; Pilliar et al., 1986). Primary press-fit fixation of femoral knee

\footnotetext{
* Corresponding author. Medical Device Research Institute, College of Science and Engineering, Flinders University, GPO Box 2100, Adelaide, South Australia, 5001, Australia.

E-mail address: egon.perilli@flinders.edu.au (E. Perilli).
} 
prostheses is obtained thanks to the inside dimensions of the implant being undersized with respect to the bone cuts created intra-operatively, dictated by a press-fit specified by the implant design (Curtis et al., 1992). However, during the implantation process, high compressive and shear stresses are generated within the bone and at the implant-bone surface, which might permanently damage the bone (Bishop et al., 2014; Berahmani et al., 2018). The extent of this damage could influence the long-term survival rates in press-fit prostheses (Taylor et al., 1998), with complications in total knee arthroplasty (revisions) typically involving both the tibial and femoral component (25.6\% of revisions) (Graves and Turner, 2018), whereas $9.7 \%$ of revisions are of the tibial component only and $5.8 \%$ are of the femoral component only (Graves and Turner, 2018). Previous studies have investigated the bone damage caused during press-fit implantation in three dimensions (3D), but were limited to trabecular bone cubes excised from the proximal femur (Bishop et al., 2014; Damm et al., 2017). To the best of our knowledge, only one study has examined actual damage created during press-fit implantation of knee implants, published by the co-authors of the present manuscript (Berahmani et al., 2018). In that study, the interference fit of a press-fit femoral knee implant was investigated, where the depth of damage to the outer surface of the bone was quantified by comparing the bone surfaces from the pre- and post-implantation images obtained using high-resolution peripheral computed tomography (HR-pQCT) and calculating the relative (normal) differences (Berahmani et al., 2018). However, the amount of internal damage and the permanent deformations within the bone (beyond its outer surface), which may also affect the primary stability of the implant (Taylor et al., 1998), are still unknown.

To study eventual micro-structural damage caused at increasing depths within the bone, high-resolution 3D imaging of the femoral condyles before and after press-fit implantation is necessary. HR-pQCT scanners allow scanning of such big specimens (which, for example, can be up to about $80 \mathrm{~mm}$ long in medial-lateral direction, $50 \mathrm{~mm}$ long in anterior-posterior direction and $70 \mathrm{~mm}$ long in inferior-superior direction) at an isotropic voxel size of $61 \mu \mathrm{m}$, which currently is the highest achievable spatial resolution clinically (Berahmani et al., 2018). By examining the pre- and post-implantation cross-section image datasets, it could be possible to quantify the bone (in terms of changes of bone volume, for example), that has been permanently displaced (or damaged) during implantation and its depth. In addition, if digital volume correlation (DVC) is applied to the 3D datasets obtained before and after implantation, it can quantify the displacement of trabecular bone and the accumulated apparent strain caused by the implantation process. DVC is a 3D image-based technique, which has the ability to compute full-field displacements and strains from materials undergoing time-lapsed computed tomography. It has been successfully employed to characterise bone mechanics under step-wise loading (Bay et al., 1999; Roberts et al., 2014), to evaluate full-field internal deformations in whole bones (Hussein et al., 2012; Tozzi et al., 2016), cancellous bone (Gillard et al., 2014; Liu and Morgan, 2007), cement-bone interface (Tozzi et al., 2016; Zhu et al., 2016), the alveolar bone surrounding dental implants and glenoid plates (Du et al., 2015; Sukjamsri et al., 2015). However, to the best of our knowledge, no study has quantified the accumulated deformation or strain, in the peri-implant bone after press-fit femoral knee implantation using DVC on human knees.

Therefore, the aim of the present ex-vivo study is to quantify, using HR-pQCT imaging $(61 \mu \mathrm{m} /$ voxel) combined with Digital Volume Correlation (DVC), volumetric bone damage and permanent bone deformation due to press-fit femoral knee implantation in human distal femurs. The implant studied was a cementless Sigma ${ }^{\circ}$ PFC cruciate retaining femoral knee implant, which is one of the most commonly used for cementless total knee replacement (Graves and Turner, 2018; Robertsson et al., 2017; NJR Editorial Board, 2018).

\section{Methods}

\subsection{Bone Specimens}

The HR-pQCT images of the six human cadaveric femora (age $85 \pm 3$ years, fresh-frozen) generated in the previous study (Berahmani et al., 2018) were used in this study. Briefly, these six femora were obtained from the Anatomy Department of the Radboud university medical center and thawed at room temperature. An experienced orthopaedic surgeon performed bone cuts following normal surgical procedure using standard intramedullary instrumentation and an oscillating saw with a blade thickness of $1.47 \mathrm{~mm}$ (DePuy Synthes, Leeds, UK). Two holes were drilled for the femoral pegs. A femoral cutting block was fixed with two threaded pins, to first resect approximately $9 \mathrm{~mm}$ of distal femur from the most prominent distal part of the condyle (Fig. 1b).

\subsection{Pre-implantation $H R-p Q C T$ scan}

The entire resected distal femurs were scanned in air with HR-pQCT (XtremeCT II, SCANCO Medical AG, Brüttisellen, Switzerland) at $60.7 \mu \mathrm{m}$ isotropic voxel size, peak voltage $68 \mathrm{kVp}$, current $1,470 \mu \mathrm{A}$ and $200 \mathrm{~ms}$ integration time. Specimen scanning occurred in 7 contiguous stacks of 168 slices each (corresponding to $10.2 \mathrm{~mm}$ length for each stack), leading to a total scanning length of $71.4 \mathrm{~mm}$ for each femur.

\subsection{Implant fitting}

The bone specimens were then fitted (five size 5 implants, one size 3) with a cementless Sigma PFC cruciate retaining femoral knee implant with porous surface coating, Porocoat ${ }^{\circ}$ (DePuy Synthesis Joint Reconstruction, Leeds, UK) by the same surgeon (Fig. 1a). This implant has a nominal interference fit of $0.75 \mathrm{~mm}$ at the anterior, posterior and distal resected planes of the femur (i.e., a total anterior-posterior interference fit of $1.5 \mathrm{~mm}$ ). This value of $0.75 \mathrm{~mm}$ is equal to the average thickness of the porous surface coating.

\subsection{Implant removal}

After implantation, the implants were split through the bottom of the condyles using an electric diamond-blade and gently removed to avoid additional bone damage.

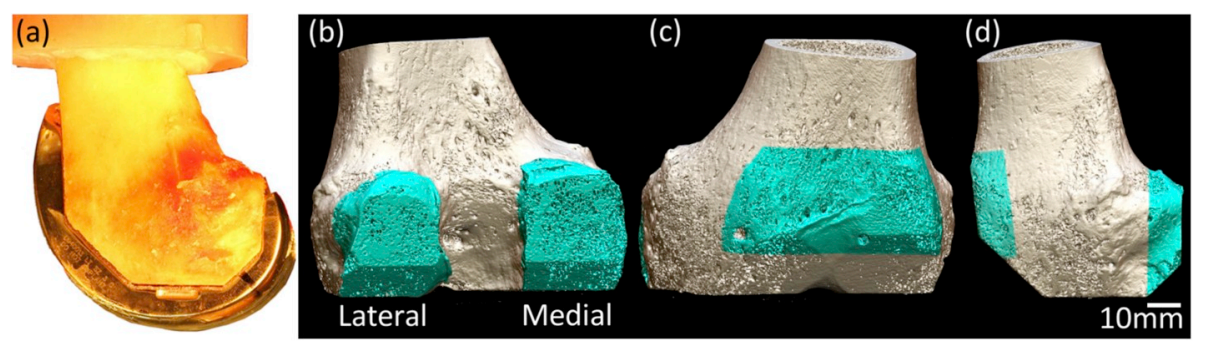

Fig. 1. (a) Photograph (lateral view) of a resected distal femur with press-fit femoral knee component; (b) HR-pQCT 3D rendering of the resected femoral condyles in posterior, (c) anterior and (d) lateral view, with volumes of interest (VOIs) used for BV/TV and DVC analysis highlighted in blue color. 


\subsection{Post-implantation HR-pQCT scan}

Subsequently, the post-implantation distal femurs were rescanned using HR-pQCT, using the same settings as in the pre-implantation HRpQCT scan (see point 2.2).

\subsection{Cross-section image reconstruction and image registration}

Cross-section images (each $1,508 \times 1,008$ pixels in size, at $60.7 \mu \mathrm{m}$ isotropic pixel size, corresponding to $91.5 \times 61.2 \mathrm{~mm}$ ) of the pre- and post-implantation scans were reconstructed using proprietary software (SCANCO v1.2a, SCANCO Medical AG, Brüttisellen, Switzerland) and then converted into 8-bit gray-scale bitmap files. Rigid 3D image registration of the pre- and post-implantation cross-section images was then performed (software DataViewer v1.5.2.4, Skyscan-Bruker, Kontich, Belgium) (Martelli and Perilli, 2018). This algorithm uses a combination of Powell's method and the sum of squares difference to find the optimal registration of the target (post-implantation scan) to the reference (pre-implantation scan) over three iterations (Press et al., 1992). Registration was performed to align the post- to the pre-implantation HR-pQCT reconstructed datasets, by aligning regions distant from the bone-implant interface by a minimum of $4 \mathrm{~mm}$, where no damage was expected to have occurred.

\subsection{Volumes of interest (VOIs)}

For each specimen, VOIs were selected using CT Analyser (SkyscanBruker, Kontich, Belgium) in the posterior and anterior condylar regions of the distal femur; these were based on visual examination of bone damage evident in the HR-pQCT images and from the actual interference fit between the implant's surface and the resected femur as previously determined from optical scanning (TRIOS Color-P13, 3Shape, Copenhagen, Denmark) on these specimens (Berahmani et al., 2018). The VOIs were selected from the cross-section image datasets in coronal view (Figs. 1 and 2). To evaluate damage to the posterior condyles, two VOIs were selected, to separately examine the posteriormedial and posterior-lateral condyle (Fig. 1b). Each VOI included a stack of 165 consecutive coronal cross-sections (rectangular shape, $34 \times 41 \mathrm{~mm}$ in size) which went $10 \mathrm{~mm}$ in depth, starting from the first posterior cross-section image (depth $=0 \mathrm{~mm}$ ) (coronal plane) that was containing the entire condyle in the pre-implantation dataset as reference (Fig. 1b and d). Similarly, to evaluate damage to the anterior condylar region, a parallelepiped VOI was individually rotated in space, to have its major cross-section (rectangular shape, $53 \times 40 \mathrm{~mm}$ in size) parallel to the resection plane. The VOI was defined to encompass the area of apparent damage for $10 \mathrm{~mm}$ of depth (165 cross-sections) in anterior-posterior direction and parallel to the resected planes of the condyles, starting from the outermost cross-section (depth $=0 \mathrm{~mm}$ ) that contained the contours of the intact condyle in the pre-implantation dataset as reference (Fig. 1c and d).

\subsection{Image segmentation and bone volume quantification}

A uniform threshold was applied to the image stacks to segment the bone tissue from air/marrow. The threshold level (65) for segmentation was defined from the gray-level histograms (256 gray-levels) of the 6 specimens (Fig. 2) (Perilli et al., 2007a, 2007b; Roberts et al., 2017). Pixels representing bone tissue (gray-level values between 65 and 255) were segmented as solid and pixels representing non-bone tissue (graylevel values between 0 and 64) as background. The bone volume fraction (BV/TV, \%), i.e. the amount of pixels classified as bone in the region of interest divided by the total area of the region (Perilli et al., 2012), was then calculated for the stack of segmented pre- and postimplantation images in each of the VOIs defined above (see 2.7). The ratio $\mathrm{BV} / \mathrm{TV}_{\text {post }} / \mathrm{BV} / \mathrm{TV}_{\text {pre }}$ was then calculated and plotted in a graph, cross-section by cross-section, at increasing coronal depth (up to
$10 \mathrm{~mm}$ ) entering the bone from its resection surface (depth $=0 \mathrm{~mm}$, defined from the pre-implantation stack), in posterior-anterior direction for the posterior condyles and in anterior-posterior direction for the anterior condylar region (Fig. $3 \mathrm{a}$ and b).

\subsection{Statistical analysis}

Examination of the graphs " $\mathrm{BV} / \mathrm{TV}_{\text {post }} / \mathrm{BV} / \mathrm{TV}_{\text {pre }}$ ratio vs. depth" revealed, for each of the six femurs, three consecutive characteristic points of interest (Fig. 3): they consisted, at increasing depth, in a minimum value for $\mathrm{BV} / \mathrm{TV}_{\text {post }} / \mathrm{BV} / \mathrm{TV}_{\text {pre }}$ ratio (point $\mathrm{A}$ ), followed by an increase up to a maximum peak (point $B$ ) and then by a partial decrease with a subsequent flattening of the curve (point C). "C" was defined as the point after which two consecutive centred 5-point moving averages of the $\mathrm{BV} / \mathrm{TV}_{\text {post }} / \mathrm{BV} / \mathrm{TV}_{\text {pre }}$ differed by less than $0.15 \%$ in value. To test the six femurs for differences in $\mathrm{BV} / \mathrm{TV}_{\text {post }} / \mathrm{BV} / \mathrm{TV}_{\text {pre }}$ ratios and in depths among these 3 characteristic points, a Friedman test was used (non-parametric analogue to a repeated measures ANOVA), followed by a post-hoc Wilcoxon signed-rank test (non-parametric analogue to a paired $t$-test). These non-parametric tests were also used to compare the $\mathrm{BV} / \mathrm{TV}_{\text {post }} / \mathrm{BV} / \mathrm{TV}_{\text {pre }}$ ratios and depths among the VOIs. Statistical significance was defined as $\mathrm{p}<0.05$. Statistical analysis was performed using SPSS Statistics 25 (IBM Corp., Armonk, NY).

\subsection{Application of $D V C$}

To quantify trabecular bone displacements and plastically accumulated strains at the micro-structural level, DVC direct correlation (DC) (DaVis v8.3.1, LaVision, Germany) was then computed on the gray-scale images constituting the VOIs pre- and post-implantation defined above (see 2.7). In brief, DVC (DC) relies on zero-mean normalised correlation as a discrete function of gray-levels for each individual sub-volume (Roberts et al., 2014; Tozzi et al., 2017). For each sub-volume, displacement is represented as a vector and strain is then derived from the displacement using a centred finite difference (CFD) scheme (Palanca et al., 2015).

\subsubsection{VOI masking for DVC and DVC computation}

To reduce background noise in the gray-scale VOIs that could produce artifacts in the DVC displacement and strain calculations, the VOIs were first masked using software CTAn to contain the bone and marrow of the posterior condyle ("shrink-wrap" function) and then masked again in DaVis (algorithmic mask), to exclude pixels belonging to background (air), while still considering trabeculae and marrow pixels within the condyle.

DVC computation was set to use $0 \%$ overlap and a 3-step multipass of 56 voxels $(3.4 \mathrm{~mm})$ side, 48 voxels $(2.9 \mathrm{~mm})$ side and a final subvolume size of 20 voxels $(1.2 \mathrm{~mm})$ side. The use of a multipass in DVC direct correlation has been shown to reduce random error for displacement in bone specimens (Tozzi et al., 2017). The computational time was $416 \mathrm{~s}$, for a multipass sub-volume of 20 voxels side for a $30 \times 35 \times 10 \mathrm{~mm}$ region, using an Intel Core i7-6700 CPU with $3.40 \mathrm{GHz}$ quad-core processor and $16 \mathrm{~GB}$ RAM. The final sub-volume size of 20 voxels side was chosen as an optimal compromise, based on measurement error calculations as explained below (see point 2.10.2).

\subsubsection{Evaluation of sub-volume size errors in DVC ('accuracy' and 'precision')}

For DVC computations, an increase in the sub-volume size leads to a decrease in the displacement and strain errors. However, this also decreases (worsens) the spatial resolution of the resultant DVC computation, which then might not be able to capture displacements in a too coarse (big) sub-volume (Roberts et al., 2014; Palanca et al., 2015). To identify the smallest suitable sub-volume size, while still maintaining an acceptable level of error, the random errors associated with both displacement and strain were computed for decreasing sub-volume 

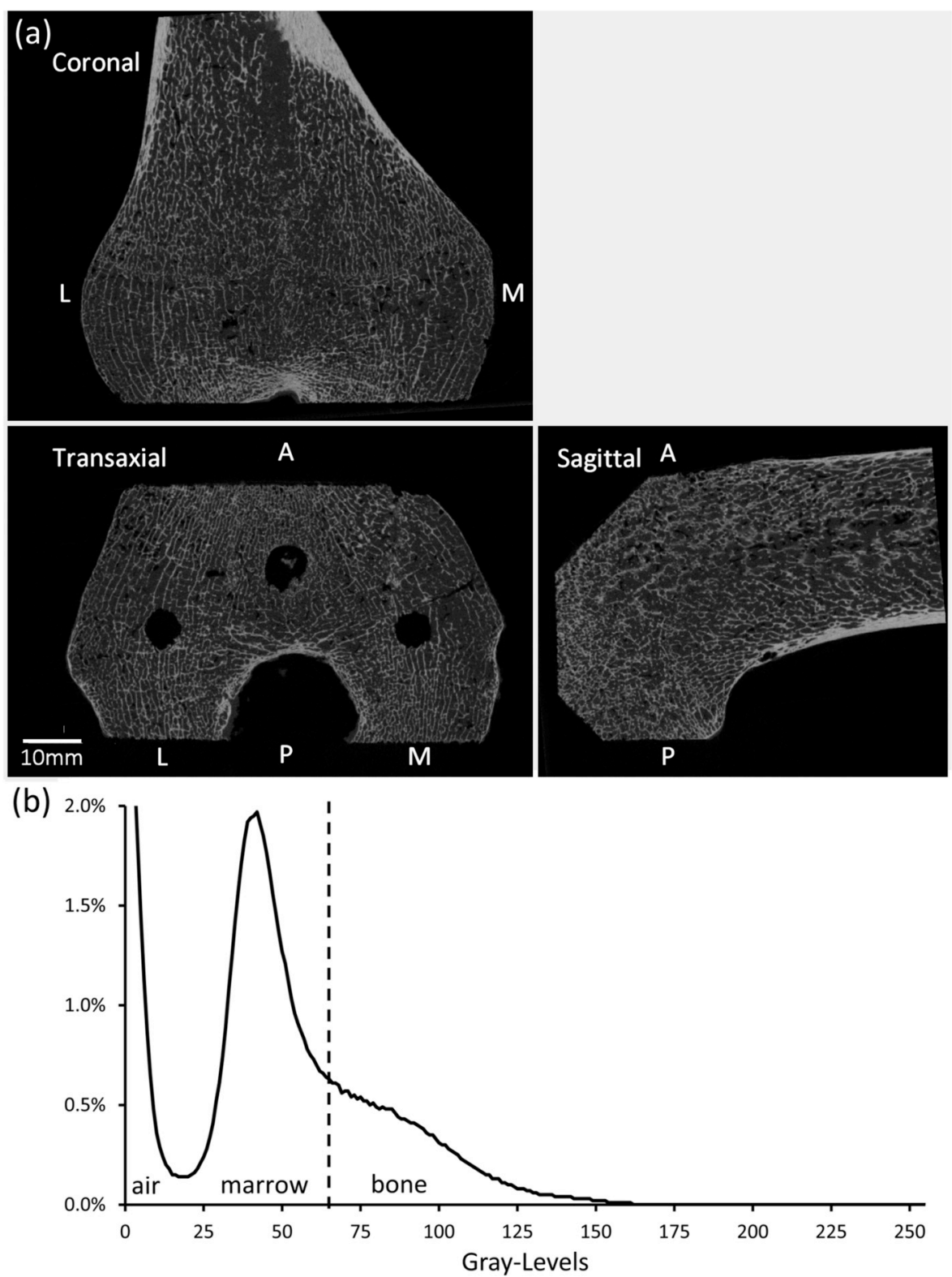

Fig. 2. a) HR-pQCT cross-section images of a resected distal femur pre-implantation, at $60.7 \mu \mathrm{m}$ isotropic pixel size (bone in bright gray color, marrow in dark gray). b) Example of a gray-level histogram (256 gray-levels) of a transaxial cross-section image. The threshold level used to segment bone from air/marrow is indicated by the dashed line (value $=65$ ). A: anterior, P: posterior, M: medial, L: lateral anatomical location.

sizes of $64,48,32$ and 20 voxels side $(3.8,2.9,1.9$ and $1.2 \mathrm{~mm}$ side lengths, respectively). This was computed for six cubical VOIs $(15 \mathrm{~mm}$ side) per three representative femur specimens, between pre- and postimplantation cross-sectional datasets, in anatomical locations distant by at least $4 \mathrm{~mm}$ from the implantation surface, where no damage was expected to have occurred (as also confirmed by the "BV/TV $\mathrm{Tost}_{\mathrm{BV}} / \mathrm{BV}$ $\mathrm{TV}_{\text {pre }}$ ratio vs. depth" analysis): in lateral-anterior (LA), lateral-posterior (LP), lateral-proximal (LPr), medial-anterior (MA), medial-posterior (MP) and medial-proximal (MPr) location (Fig. 4).

The mean absolute error (MAER) (eq. (1)) and standard deviation error (SDER) (eq. (2)) (Tozzi et al., 2017), indicators of 'accuracy' and 'precision', respectively (Liu and Morgan, 2007), were calculated in the cubical VOIs defined above, to assess strain uncertainties under zerostrain conditions. While the displacements between pre- and post-implantation in these regions (MAER) are expected to be close to zero due to the co-registration, the actual displacements measured by DVC can be affected by experimental factors (i.e. specimens were removed from scanner between scans, inaccuracies due to HR-pQCT stepper motor precision, image noise, etc) and have to be quantified. Consequently, the displacement and strain uncertainties were quantified in terms of SDER.

$M A E R=\frac{1}{N} \sum_{k=1}^{N}\left(\frac{1}{6} \sum_{c=1}^{6}\left|\varepsilon_{c, k}\right|\right)$

$S D E R=\sqrt{\frac{1}{N} \sum_{k=1}^{N}\left(\frac{1}{6} \sum_{c=1}^{6}\left|\varepsilon_{c, k}\right|-M A E R\right)^{2}}$

$\varepsilon=$ strain, $\mathrm{c}=$ independent strain component, $\mathrm{k}=$ measurement point, $\mathrm{N}=$ number of measurement points. 
(a)

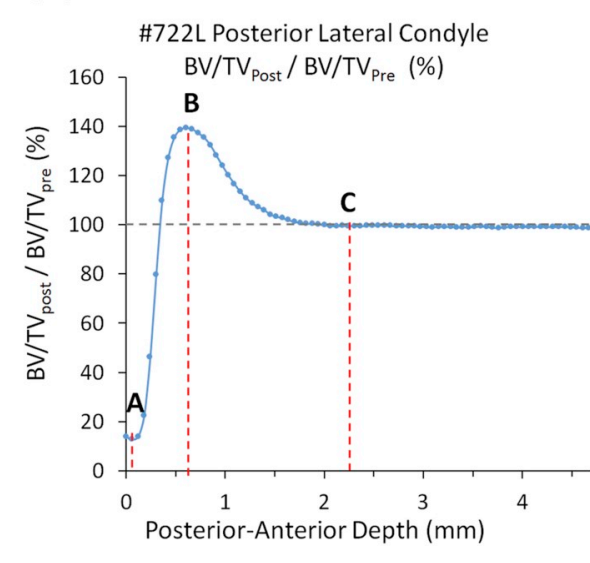

(b)

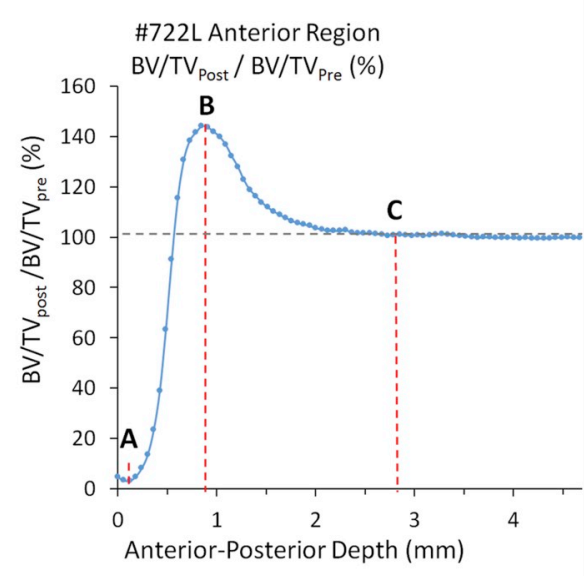

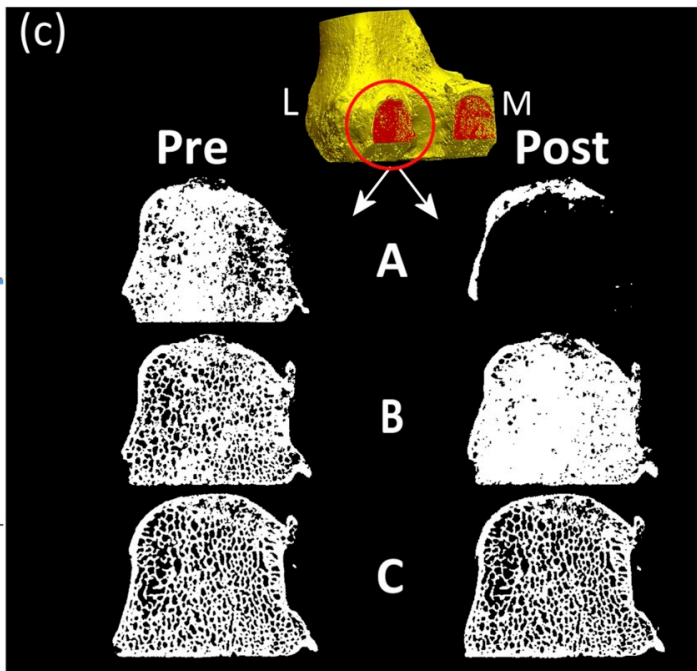

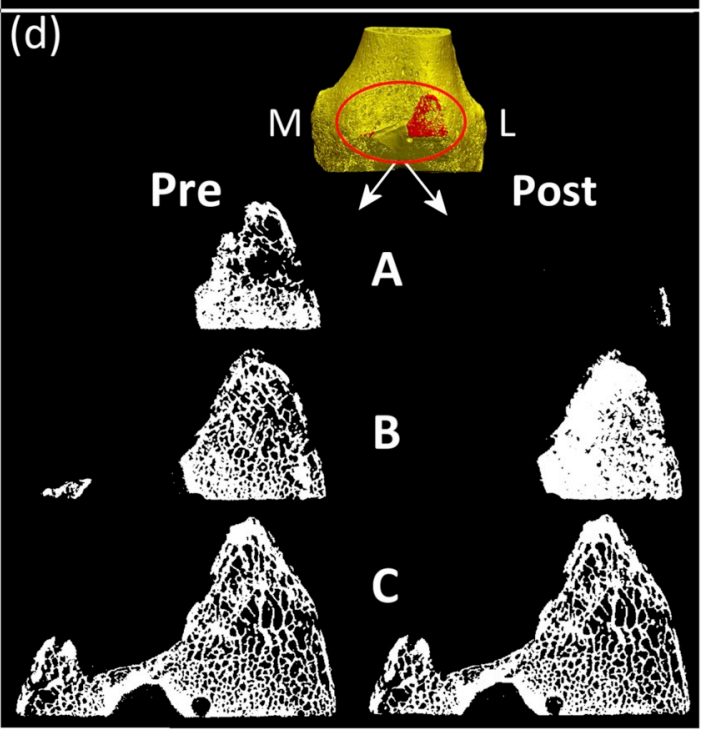

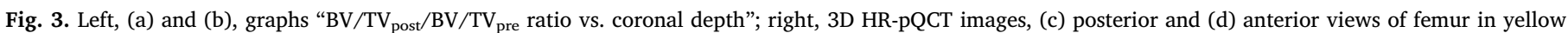

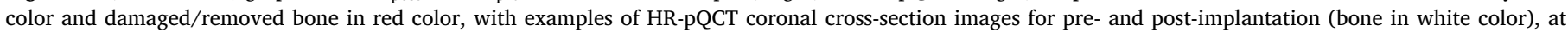
increasing coronal depth from the bone surface, showing characteristic points: A peak bone removal, B peak compaction, $\mathbf{C}$ unchanged.

\section{Results}

\subsection{Bone volume}

\subsubsection{Posterior locations}

The "BV/TV $\mathrm{Tost}_{\text {(BV/TV }} / \mathrm{TV}_{\text {pre }}$ ratio vs. depth" graphs (Fig. 3a) and corresponding HR-pQCT images showed, consistently among the six femurs, three consecutive regions of interest with characteristic points of interest, differing significantly in $\mathrm{BV} / \mathrm{TV}_{\text {post }} / \mathrm{BV} / \mathrm{TV}_{\text {pre }}$ ratios and depth among each other $(p=0.028$, Table 1$)$. On average, the first part of the graph showed $\mathrm{BV} / \mathrm{TV}_{\text {post }} / \mathrm{BV} / \mathrm{TV}_{\text {pre }}$ ratio $<100 \%$, with a minimum peak $\left(\mathrm{A}, \mathrm{BV} / \mathrm{TV}_{\text {post }} / \mathrm{BV} / \mathrm{TV}_{\text {pre }}\right.$ ratio $=27.9 \pm 15.1 \%$ posterior-lateral, $28.5 \pm 28.3 \%$ posterior-medial, mean $\pm \mathrm{SD}$ ) which occurred at $0.1 \pm 0.1 \mathrm{~mm}$ depth posterior-lateral and $0.0 \pm 0.0 \mathrm{~mm}$ depth posterior-medial. This was followed by an increase up to a maximum value $>100 \%$ suggesting bone compaction, with a maximum peak (B, BV $/ \mathrm{TV}_{\text {post }} / \mathrm{BV} / \mathrm{TV}_{\text {pre }}$ ratio $=140.1 \pm 33.3 \%$ posteriorlateral, $150.6 \pm 39.9 \%$ posterior-medial) at $1.0 \pm 0.6 \mathrm{~mm}$ depth posterior-lateral and $0.7 \pm 0.2 \mathrm{~mm}$ depth posterior-medial. Then there was a partial decrease with subsequent flattening of the curve at values approaching $100 \%$, suggesting no changes between pre- and post-implantation $\left(\mathrm{C}, \mathrm{BV} / \mathrm{TV}_{\text {post }} / \mathrm{BV} / \mathrm{TV}_{\text {pre }}\right.$ ratio $=98.1 \pm 0.5 \%$ posterior-lateral, $98.0 \pm 0.5 \%$ posterior-medial) at $2.3 \pm 0.5 \mathrm{~mm}$ depth posterior- lateral and $1.7 \pm 0.3 \mathrm{~mm}$ depth posterior-medial.

\subsubsection{Anterior locations}

Also the "BV/TV $\mathrm{Tost}_{\mathrm{BV}} / \mathrm{TV}_{\text {pre }}$ ratio vs. depth" graphs (Fig. 3b) for the anterior regions showed three consecutive regions of interest that differed in both $\mathrm{BV} / \mathrm{TV}_{\text {post }} / \mathrm{BV} / \mathrm{TV}_{\text {pre }}$ ratio and depth $(\mathrm{p}=0.028$, Table 1). First, a minimum peak (A, BV/TV ${ }_{\text {post }} / \mathrm{BV} / \mathrm{TV}_{\text {pre }}$ ratio $=3.9 \pm 4.2 \%$ ) occurred at $0.0 \pm 0.1 \mathrm{~mm}$ depth; then, at increasing depth, the $\mathrm{BV} / \mathrm{TV}_{\text {post }} / \mathrm{BV} / \mathrm{TV}_{\text {pre }}$ ratio increased to a maximum peak above $100 \%\left(\mathrm{~B}, \mathrm{BV} / \mathrm{TV}_{\text {post }} / \mathrm{BV} / \mathrm{TV}_{\text {pre }}\right.$ ratio $\left.=127.1 \pm 12.1 \%\right)$ occurring at $0.8 \pm 0.1 \mathrm{~mm}$ depth. $\mathrm{BV} / \mathrm{TV}_{\text {post }} / \mathrm{BV} / \mathrm{TV}_{\text {pre }}$ ratios then reached a plateau at increasing depth, suggesting no changes (C, BV/ $\mathrm{TV}_{\text {post }} / \mathrm{BV} / \mathrm{TV}_{\text {pre }}$ ratio $\left.=101.1 \pm 1.6 \%\right)$ at $2.1 \pm 0.4 \mathrm{~mm}$ depth.

When comparing the $\mathrm{BV} / \mathrm{TV}_{\text {post }} / \mathrm{BV} / \mathrm{TV}_{\text {pre }}$ ratio among the posterior-medial, posterior-lateral and anterior VOIs (Table 1 ), the anterior VOI showed statistically significant lower values compared to the posterior-medial VOI $(\mathrm{p}=0.043)$ and to the posterior-lateral VOI $(\mathrm{p}=0.028)$ at point $\mathrm{A}$. The anterior VOI also showed slightly higher values at point $\mathrm{C}$ compared to the posterior-medial and posterior-lateral VOIs $(\mathrm{p}=0.028)$. No significant differences in depth among the VOIs were found for the points $\mathrm{A}, \mathrm{B}, \mathrm{C}$. 


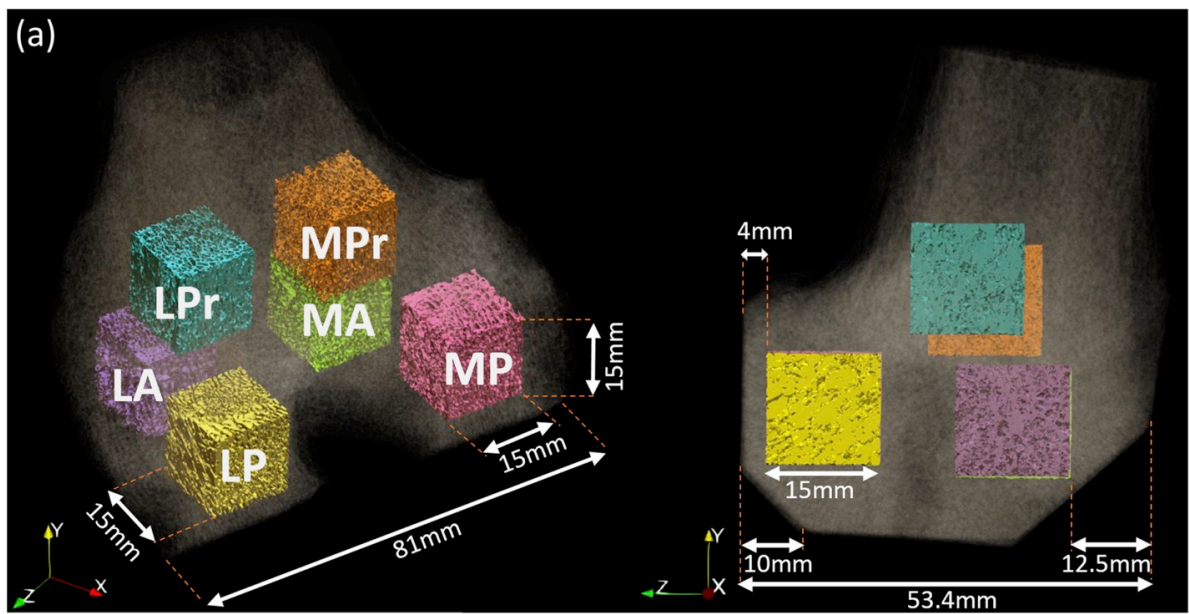

Fig. 4. (a) Volumes of interest (cubes of $15 \mathrm{~mm}$ side length) used for the evaluation of strain uncertainties (MAER and SDER) in "zero-strain" conditions, away from the bone-implant interface by a minimum of $4 \mathrm{~mm}$ distance: lateral-anterior (LA), lateral-posterior (LP), lateral-proximal (LPr), medial-anterior (MA), medial-posterior (MP) and medial-proximal (MPr) location. (b) Example of strain uncertainties computed by DVC for the principal strains for a sub-volume of 20 voxels side ( $1.2 \mathrm{~mm}$ side length) (i) $\varepsilon_{\mathrm{xx}}$, (ii) $\varepsilon_{\mathrm{yy}}$ and (iii) $\varepsilon_{\mathrm{zz}}$, under "zero-load" conditions in the $\mathrm{LPr}$ cube.

(b)
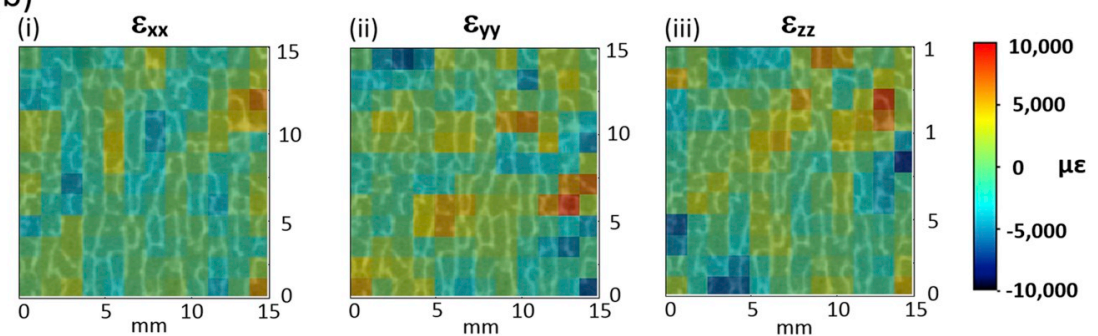

Table 1

"BV/TV ${ }_{\text {post }} / \mathrm{BV} / \mathrm{TV}_{\text {pre }}$ ratio (\%) vs. coronal depth $(\mathrm{mm})$ ", summary: Average values \pm standard deviation (n $=6$ femurs) of $\mathrm{BV} / \mathrm{TV} \mathrm{post}_{\mathrm{p}} / \mathrm{BV} / \mathrm{TV}$ pre ratio (\%) and coronal depth (mm) from the bone surface at the characteristic points A, B and C identified in the corresponding graphs (Fig. 3), for posterior-lateral, posterior-medial and anterior VOIs.

\begin{tabular}{|c|c|c|c|}
\hline & \multicolumn{3}{|c|}{ Characteristic points: } \\
\hline & A & в & C \\
\hline \multicolumn{4}{|l|}{ Posterior-lateral VOI } \\
\hline $\mathrm{BV} / \mathrm{TV}_{\text {post }} / \mathrm{BV} / \mathrm{TV}_{\text {pre }}$ ratio (\%) & $27.9 \pm 15.1^{\mathrm{a}, \mathrm{b}}$ & $140.1 \pm 33.3^{\mathrm{a}}$ & $98.1 \pm 3.5^{\mathrm{a}, \mathrm{b}}$ \\
\hline Depth $(\mathrm{mm})$ & $0.1 \pm 0.1^{\mathrm{a}}$ & $1.0 \pm 0.6^{\mathrm{a}}$ & $2.3 \pm 0.5^{\mathrm{a}}$ \\
\hline \multicolumn{4}{|l|}{ Posterior-medial VoI } \\
\hline $\mathrm{BV} / \mathrm{TV}_{\text {post }} / \mathrm{BV} / \mathrm{TV}_{\text {pre }}$ ratio (\%) & $28.5 \pm 28.3^{\mathrm{a}, \mathrm{c}}$ & $150.6 \pm 39.9^{\mathrm{a}}$ & $98.0 \pm 0.5^{\mathrm{a}, \mathrm{c}}$ \\
\hline Depth $(\mathrm{mm})$ & $0.0 \pm 0.0^{\mathrm{a}}$ & $0.7 \pm 0.2^{\mathrm{a}}$ & $1.7 \pm 0.3^{\mathrm{a}}$ \\
\hline \multicolumn{4}{|l|}{ Anterior VOI } \\
\hline $\mathrm{BV} / \mathrm{TV}_{\text {post }} / \mathrm{BV} / \mathrm{TV}_{\text {pre }}$ ratio (\%) & $3.9 \pm 4.2^{a, b, c}$ & $127.1 \pm 12.1^{\mathrm{a}}$ & $101.1 \pm 1.6^{\mathrm{a}, \mathrm{b}, \mathrm{c}}$ \\
\hline Depth (mm) & $0.0 \pm 0.1^{\mathrm{a}}$ & $0.8 \pm 0.1^{\mathrm{a}}$ & $2.1 \pm 0.4^{\mathrm{a}}$ \\
\hline
\end{tabular}

\footnotetext{
${ }^{a}$ Significant differences between points A, B and C within the specified VOI (Friedman test, followed by a post-hoc Wilcoxon signed rank test, $\mathrm{p}<0.05)$.

b Significant difference between posterior-lateral and anterior VOIs at a given characteristic point (Friedman test, followed by a post-hoc Wilcoxon signed rank test, $\mathrm{p}<0.05$ ).

c Significant difference between posterior-medial and anterior VOIs at a given characteristic point (Friedman test, followed by a post-hoc Wilcoxon signed rank test, $\mathrm{p}<0.05$ ).
}

\subsection{DVC results}

\subsubsection{Posterior locations}

The displacement of trabecular bone computed by DVC suggested that bone compaction occurred in depths up to $2.6 \pm 0.8 \mathrm{~mm}$ posterior-laterally and $2.3 \pm 0.7 \mathrm{~mm}$ posterior-medially (Fig. 5b, Table 2 ), with peak third principal strains of $-162,100 \pm 55,000 \mu \varepsilon$ posteriorlaterally and $-138,900 \pm 12,200 \mu \varepsilon$ posterior-medially (MAER 1,000-2,000 $\mu \varepsilon$, SDER 200-500 $\mu \varepsilon$ ) (Fig. 5c), the negative sign being consistent with mechanical compression. High localised compressive strains were apparent at the surface of the posterior condyles $(-80,000$ $\mu \varepsilon$ to $-100,000 \mu \varepsilon$ ) and were completely confined within the first $2.6 \mathrm{~mm}$ of posterior-anterior depth.

\subsubsection{Anterior locations}

In the anterior regions, DVC suggested that compaction of trabecular bone occurred up to $2.1 \pm 0.3 \mathrm{~mm}$ in depth (Fig. 5b, Table 2), with peak third principal strains of $-167,900 \pm 38,600 \mu \varepsilon$ (MAER 1,000-2,000 $\mu \varepsilon$, SDER 200-500 $\mu \varepsilon$ ) (Fig. 5d). High localised compressive strains were apparent at the surface $(-60,000$ to $-90,000 \mu \varepsilon)$, dissipating with increasing anterior-posterior depth and were completely confined within the first $2.1 \mathrm{~mm}$ depth.

\subsubsection{DVC errors at varying sub-volume size (accuracy, precision)}

The strain error decreased non-linearly when the sub-volume size was increased (Fig. S-1). Zero-strain testing indicated that a sub-volume of 20 voxels side ( $1.2 \mathrm{~mm}$ ) had a strain MAER 1,000-2,000 $\mu \varepsilon$ and SDER 

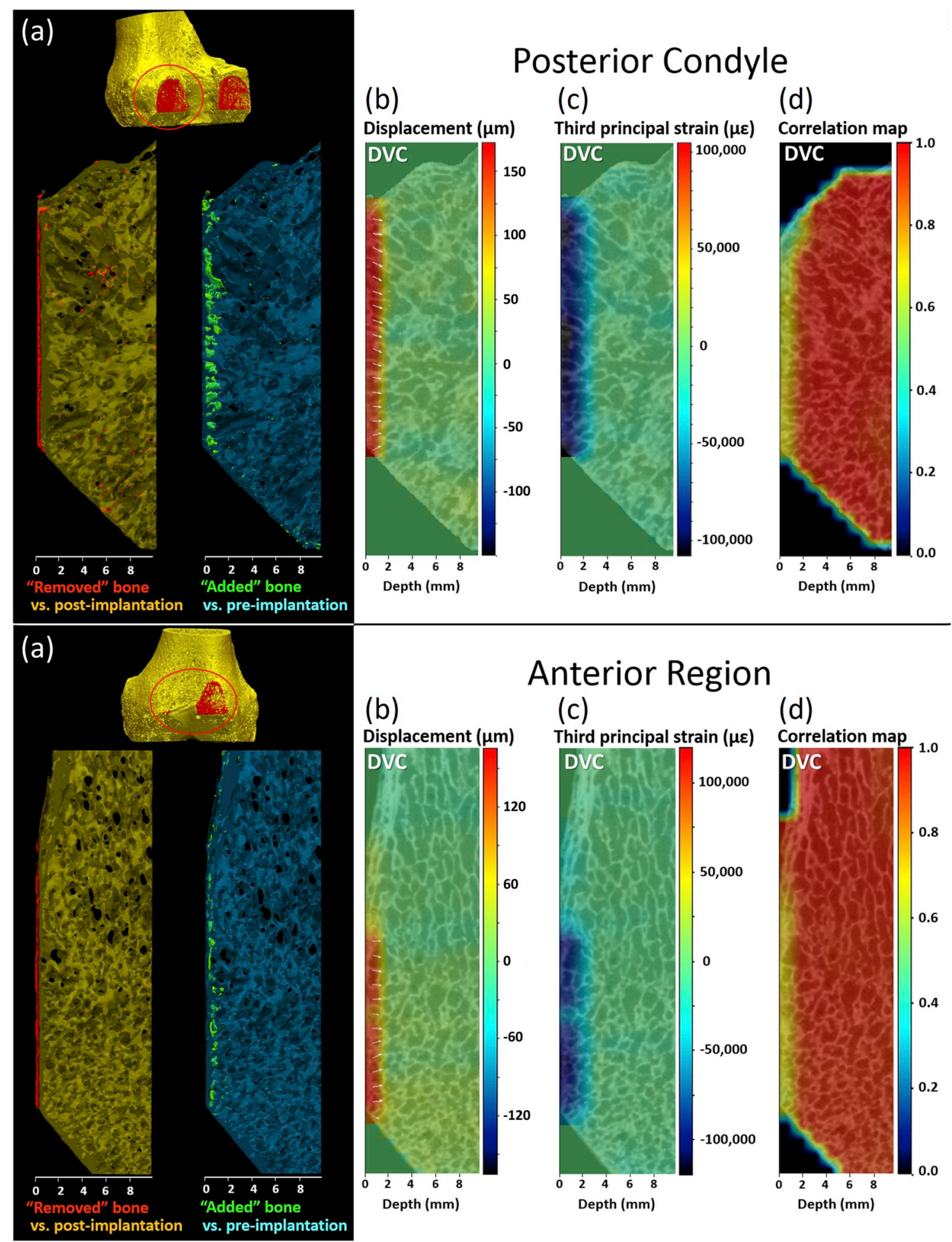

\section{Anterior Region}

(c) (d)

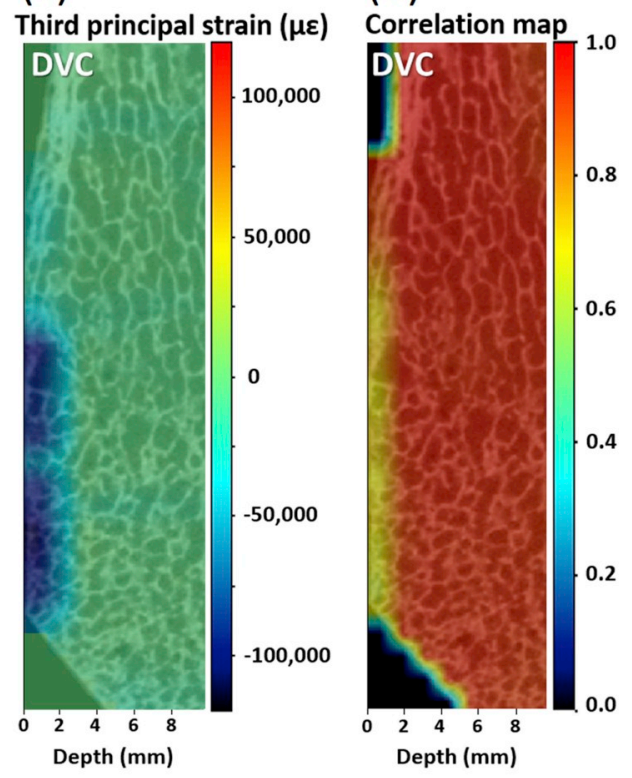

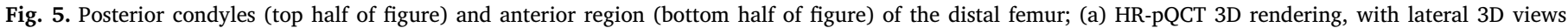

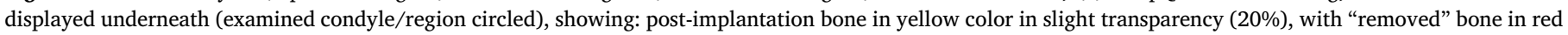

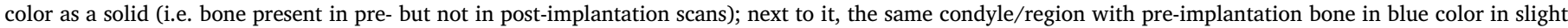

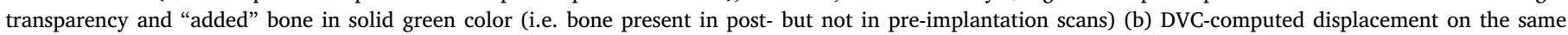

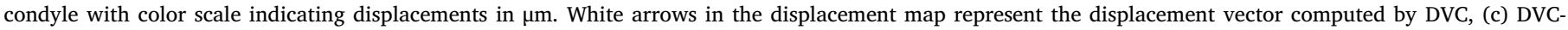

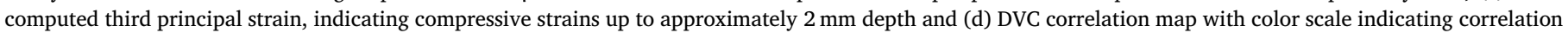
coefficients.

200-500 $\mu \varepsilon$, with a SDER for displacement for each region below 0.08 pixels $(4.92 \mu \mathrm{m})$. As permanent deformation is being investigated in this study and the yield strain of bone is 7,000 to $10,000 \mu \varepsilon$ (Bayraktar et al., 2004; Morgan and Keaveny, 2001), this level of precision error
$(2-7 \%)$ is still deemed acceptable, as it is less than $10 \%$ of the nominal strain (Bay et al., 1999; Roberts et al., 2014; Liu and Morgan, 2007). This sub-volume size is also small enough to capture the bone displacements as suggested by the BV/TV changes in the curve, which 
Table 2

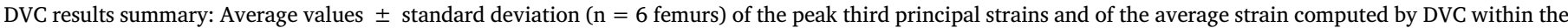
first few $\mathrm{mm}$ of depth from the bone surface, for posterior-lateral, posterior-medial and anterior VOIs.

\begin{tabular}{|c|c|c|c|}
\hline & Depth (mm) & Peak third principal strains within depth $(\mu \varepsilon)$ & Average strain within depth $(\mu \varepsilon)$ \\
\hline Posterior-lateral VOI & $2.6 \pm 0.8$ & $-162,100 \pm 55,000$ & $-39,300 \pm 22,400$ \\
\hline Posterior-medial VOI & $2.3 \pm 0.7$ & $-138,900 \pm 12,200$ & $-41,300 \pm 24,400$ \\
\hline Anterior VOI & $2.1 \pm 0.3$ & $-167,900 \pm 38,600$ & $-25,300 \pm 18,800$ \\
\hline
\end{tabular}

The "depth" here is defined as the first coronal depth beyond which the average computed displacement dropped to values below a threshold of 0.4 pixels $(=0.02 \mathrm{~mm})$. This threshold value corresponds to the "zero-strain conditions" (see point 2.10.2 Methods) displacement accuracy (MAER) plus standard deviation (SDER) computed by DVC, over three representative specimens (Fig. S-1).

appear occurring at distance intervals less than $3 \mathrm{~mm}$ (Fig. 3a). Therefore, the sub-volume of 20 voxels side was chosen for the DVC analysis in this manuscript (see point 2.10.1 in Methods).

\section{Discussion}

This study investigated the permanent bone damage that occurs due to press-fit femoral knee implantation in 3D, quantifying bone microarchitectural damage through the use of HR-pQCT quantitative image analysis and DVC techniques.

The $\mathrm{BV} / \mathrm{TV}_{\text {post }} / \mathrm{BV} / \mathrm{TV}_{\text {pre }}$ ratio for the investigated VOIs (posteriormedial, posterior-lateral condyles and anterior region) indicated on average an apparent permanent bone damage up to $2.3 \mathrm{~mm}$ in depth, with three characteristic regions within this depth (Fig. 3). Initially, the $\mathrm{BV} / \mathrm{TV}_{\text {post }} / \mathrm{BV} / \mathrm{TV}_{\text {pre }}$ ratio is less than $100 \%$ indicating bone removal (A) in the post-implantation scan. The $\mathrm{BV} / \mathrm{TV}_{\text {post }} / \mathrm{BV} / \mathrm{TV}_{\text {pre }}$ ratio then rises to a peak above $100 \%$ (B) at increasing depth, indicating the compaction of trabecular bone. Finally, the $\mathrm{BV} / \mathrm{TV}_{\text {post }} / \mathrm{BV} / \mathrm{TV}_{\text {pre }}$ ratio levels out to approximately $100 \%$ indicating no changes between preand post-implantation scans, where no further damage occurs. These findings are in line 1) with the DVC results, which suggest compaction of bone during implantation at the corresponding depths and 2) with the observed damage visible in the co-registered HR-pQCT coronal cross-section images in the pre- and post-implantation datasets (Fig. 3c and d).

A previous study, using optical scanning (Berahmani et al., 2018) on the same femurs and press-fit implant, reported bone damage to the outer surface in terms of distance between the pre- and post-implantation surfaces. Briefly, surface meshes of the pre- and post-implantation femurs from the HR-pQCT scans were co-registered and average posterior-anterior distances between pre- and post-implantation surface measured, at the posterior and anterior condylar regions. The recorded distance between pre- and post-implantation in the posterior condyles and anterior regions ranged up to $1.5 \mathrm{~mm}$. The actual interference fit measured in that study was $1.48 \pm 0.27 \mathrm{~mm}$ (mean $\pm \mathrm{SD}$ ), with variations among the implant-bone contact areas which may be attributed to cutting error and the placement of the implant (Berahmani et al., 2018). Interestingly, those reported depths are lower than the $\mathrm{BV} / \mathrm{TV}_{\text {post }} / \mathrm{BV} / \mathrm{TV}_{\text {pre }}$ posterior-anterior depth of trabecular bone damage calculated in this study by HR-pQCT (up to $2.3 \mathrm{~mm}$ ) on the same specimens. Therefore, the present results indicate that bone is actually permanently damaged also internally, in depth, beyond its interface with the implant. However, from a clinical perspective, it is unclear whether this damage impedes, or assists, in initial primary stability of the implant and resultant osseointegration into the porous surface of the implant coating (Green et al., 1999; Kold et al., 2005; Tabassum et al., 2011; Bosshardt et al., 2011).

Statistical differences in $\mathrm{BV} / \mathrm{TV}_{\text {post }} / \mathrm{BV} / \mathrm{TV}_{\text {pre }}$ ratio between the posterior and anterior VOIs were observed at points A (peak bone removal) and $\mathrm{C}$ (unchanged). At point $\mathrm{A}$, this difference can be attributed to differences in the contact area between the implant and the bone, as follows. As displayed in the photograph of a resected distal femur with press-fit femoral knee component, in the posterior condyles the implant does not completely cover the bone surface in the proximal aspect (Fig. 6a, circled in red color). During the implant fitting process (impaction), the uncovered part in the posterior condyle is not pushed in like the rest of the condyle, which creates an external "rim" of bone, visible in the HR-pQCT 3D rendering of the specimen post-implantation (Fig. 6b, red arrows). This bone rim in the posterior condyles VOI leaves more bone in the post-implantation cross-section images near to the surface (rim visible also in Fig. 3c and d, bone in white color), compared to the anterior VOI. Consequently, this led to a higher BV/TV $\mathrm{BV} / \mathrm{TV}_{\text {pre }}$ ratio (24\% actual difference, Table 1$)$ in the posterior regions than in the anterior region at point $\mathrm{A}$. Whereas at point $\mathrm{C}$, the small difference in the $\mathrm{BV} / \mathrm{TV}_{\text {post }} / \mathrm{BV} / \mathrm{TV}_{\text {pre }}$ ratio between posterior and anterior VOIs (3\% difference) is likely due to re-scanning/co-registration artifacts as explained below. We determined the standard deviation error (SDER) of the $\mathrm{BV} / \mathrm{TV}_{\text {post }} / \mathrm{BV} / \mathrm{TV}_{\text {pre }}$ calculations of the images after co-registration, by calculating the $\mathrm{BV} / \mathrm{TV}_{\text {post }} / \mathrm{BV} / \mathrm{TV}_{\text {pre }}$ in the same cubes used for the error analysis in strain, between the pre- and postimplantation cross-sectional datasets. This revealed a SDER of $2.22 \%$ in $\mathrm{BV} / \mathrm{TV}_{\text {post }} / \mathrm{BV} / \mathrm{TV}_{\text {pre }}$ ratio. As the difference in the $\mathrm{BV} / \mathrm{TV}_{\text {post }} / \mathrm{BV} / \mathrm{TV}_{\text {pre }}$ ratio at point $C$ between the posterior and anterior VOIs ( $3 \%$ difference) is of similar magnitude of the SDER in repeated scans, we conclude that
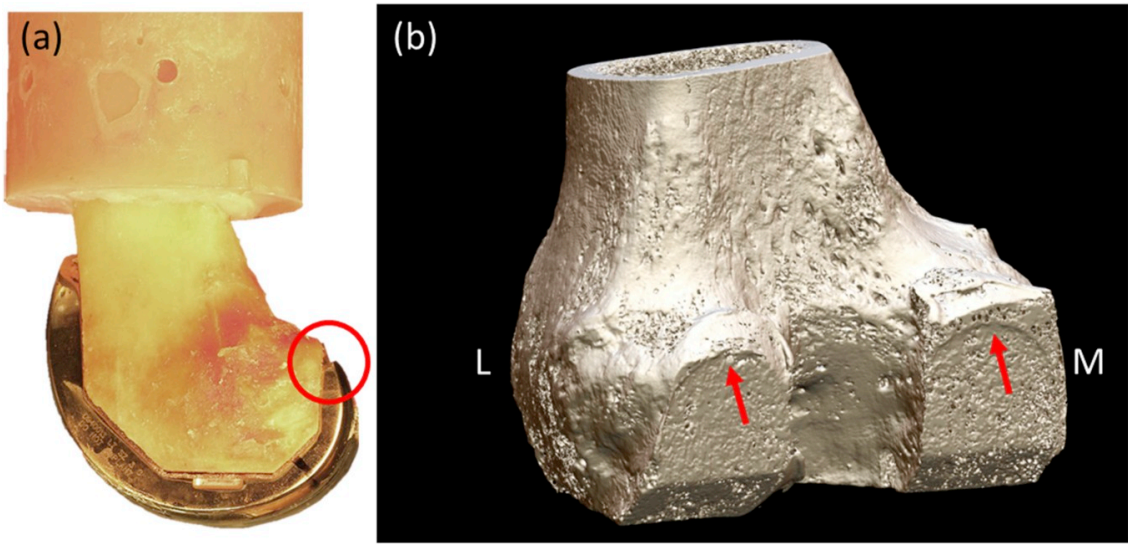

Fig. 6. (a) Photograph (lateral view) of a resected distal femur with implanted press-fit femoral knee component; circled in red color: part of bone not covered by the implant in the posterior condyle. (b) During the implant fitting process (impaction), the uncovered part in the posterior condyle is not pushed in like the rest of the condyle, which creates an external "rim" of bone, visible in the HR-pQCT 3D rendering of the specimen post-implantation (Fig. 6b, red arrows). 
this is likely due to a scanning/co-registration artifact.

The third principal strains measured by DVC in posterior condyles were consistent with mechanical compression. The strain MAER and SDER were relatively high compared to errors in DVC analysis of trabecular bone previously reported in the literature (i.e. MAER of $1,000-2,000 \mu \varepsilon$, SDER $200-500 \mu \varepsilon$ in this study, vs. MAER of about 500 $\mu \varepsilon$ and SDER of 150-200 $\mu \varepsilon$ reported for DVC analysis on human vertebral bodies using a sub-volume of 40 voxels side) (Liu and Morgan, 2007). However, the SDER of the smaller sub-volume size used in this study, 20 voxels side $(1.2 \mathrm{~mm})$, was deemed suitable to investigate postyield strain, being less than $10 \%$ of the yield strength of bone (Roberts et al., 2014). The resultant strains measured here were well above the yield strength of bone (7,000-10,000 $\mu \varepsilon$ (Bayraktar et al., 2004; Morgan and Keaveny, 2001)) indicating that permanent bone deformation occurred, in line with the changes observed in $\mathrm{BV} / \mathrm{TV}_{\text {post }} / \mathrm{BV} / \mathrm{TV}_{\text {pre }}$ ratios for the posterior and anterior condyles. Furthermore, while zero-load testing in this study of larger sub-volume sizes e.g. 48 voxels $(2.9 \mathrm{~mm})$ side had a lower strain of 300-800 $\mu \varepsilon$ and SDER between 100 and 400 $\mu \varepsilon$ (Fig S-1), that size of sub-volume $(2.9 \mathrm{~mm}$ side) would have been too large (not sensitive enough) to capture the bone displacements by the BV/TV changes in the curve (Fig. 3a).

This study measured the permanent bone deformations for one of the most commonly used implant types for cementless total knee replacement (cruciate retaining cementless Sigma ${ }^{\circ}$ PFC, DePuy Synthes Joint Reconstruction, Leeds, UK) (Graves and Turner, 2018; Robertsson et al., 2017; NJR Editorial Board, 2018), having a 10-year survival rate of $94.7 \%$, similar to that of other commonly used cementless knee implants (Graves and Turner, 2018). Hence, it would be of interest to compare the present findings against other implants (for example, with different surface coatings, press-fit values, shape) using the image analysis protocol presented. The methods and data presented can also be used to advance and validate computational models by providing information about the bone-implant interface obtained experimentally. Future studies using these methods can assist in determining the influence of bone damage on implant stability and the subsequent osseointegration, advancing implant design.

Previous studies investigated the influence of bone damage on implant stability using pull-out force as a surrogate for primary stability in press-fit implantation on excised trabecular bone cubes of mediumdensity from human femoral heads (Bishop et al., 2014; Damm et al., 2017). Their reported findings suggest that the amount of bone abrasion and compaction varies based on surface coating of the implant and the type of implantation (e.g. radial vs. axial implantation). It has also been argued that the compaction of trabecular bone may assist in primary fixation of the implant as researched in canine models (Green et al., 1999; Kold et al., 2005). Furthermore, the trabecular bone damage may even be advantageous, to an extent, possibly stimulating bone ingrowth (Tabassum et al., 2011; Bosshardt et al., 2011). However, to evaluate osseointegration clinically in femoral knee implants, a longitudinal study would be required, with patients scanned at various time points after implant surgery. In theory this may be possible with a HR-pQCT system similar to that used in this study, as it has already been used to scan human knees in vivo (Kroker et al., 2017) forging a path to potentially monitor osseointegration after implantation in vivo; however, metal artifacts in the cross-section images, due to the presence of the implanted prosthesis, might still be a strong restraining factor.

In this study, the HR-pQCT scans were performed before implantation and after implant removal, with the femurs being repositioned inside the scanner between the scans. As such, the DVC tracking in regions where notable deformation of trabeculae would have occurred was not ideal, as it was not progressive and physically these regions were located at the outer compacted surface; this is also evident by the lower correlation coefficients in these areas compared to the remainder of the specimen (Fig. 5d). However, the correlation coefficients were still within $0.5-0.75$ in the deformed regions and the measured displacements corresponded to the observed damage within the same plane (Fig. 5d); the correlation coefficients in these regions compare also favourably with those of previous studies examining compacted bone in incremental axial compression tests (Gillard et al., 2014).

This study has some limitations. Firstly, ideally, strain uncertainties would have been quantified from repeated scans of the bone specimens on which no load at all had been applied, in the same VOIs at the bone surface (posterior-medial, posterior-lateral and anterior regions) where bone damage was then investigated in this study. However, these repeated scans were not available and therefore, strain uncertainties were quantified in assumed zero-strain conditions from pre- and post-implantation scans; the strain uncertainties were assessed in 6 separate regions, away from the surfaces of impaction by at least $4 \mathrm{~mm}$ distance, where no damage was expected to have occurred (based on the "BV/ $\mathrm{TV}_{\text {post }} / \mathrm{BV} / \mathrm{TV}_{\text {pre }}$ ratio vs. depth" graphs). This possibly produced lower strain uncertainties compared to VOIs at the surface, as it did not take into account potential edge artifacts. Additionally, as the implant was removed prior to the post-implantation HR-pQCT scan, despite careful sectioning, this may have caused additional bone damage; to minimise this, the implants were split through the bottom of the condyles and gently removed. However, a few small fragments of bone were observed embedded in the porous surface of the implant after removal. This may have impacted the tracking abilities of the DVC algorithm, with reduced correlation coefficients near the implantation surface; however, these were still acceptable (between 0.5 and 0.75 , as mentioned above). Secondly, a limited sample size was used in this study (6 femurs). To account for this, non-parametric statistical tests (Friedman test, followed by post-hoc Wilcoxon signed rank test) were used for the statistical comparisons, instead of parametric tests. Nonetheless, statistically significant differences were found in $\mathrm{BV} / \mathrm{TV}_{\text {post }} / \mathrm{BV} / \mathrm{TV}_{\text {pre }}$ and depth among the 3 characteristic points of interest for the 6 specimens. Thirdly, the resection and subsequent implantation of the prosthesis was performed by only one orthopaedic surgeon. Whereas this might have reduced surgical variability, it might have introduced a systematic bias, with surgical technique possibly having an effect on the trabecular bone damage generated due to cutting errors and implant fitting affecting the interference fit of the implant (Berahmani et al., 2018; Hungerford, 1991). Femoral resections were, however, performed according to normal surgical procedure by an experienced surgeon using standard intra-medullar instrumentation. Fourthly, the spatial resolution of the 3D reconstructed images from HR-pQCT was $60.7 \mu \mathrm{m}$ isotropic voxel size. This is a relatively low spatial resolution compared to other studies computing DVC on trabecular bone (Roberts et al., 2014). This may have resulted in some errors in resolving thin trabeculae (e.g. due to partial volume effects) (Roberts et al., 2014; Perilli et al., 2012; Basler et al., 2011). However, this is currently the highest isotropic spatial resolution for a pre-clinical CT scanner that can be used on humans in an in vivo setting.

It should also be noted that when scanning the specimens with the HR-pQCT (XtremeCT II), scanning occurred in 7 batches of 168 slices $(10.2 \mathrm{~mm})$. This caused small discontinuities ("stitching artifacts") in the reconstructed scans at these intervals, noticeable to a greater degree in some specimens ( 2 out of 6 ). These discontinuities have previously been reported using the same scanner (Kroker et al., 2017). To minimise the effect of these stitching artifacts in the more affected specimens, 3D registration was focused within the same image batch where damaged occurred, but still distal from the bone-implant interface.

\section{Conclusions}

High-resolution 3D imaging combined with digital volume correlation (DVC) enabled us to detect, visualize, classify and volumetrically quantify permanent bone damage occurring due to the press-fit femoral knee implantation process. The apparent damage occurs up to $2.3 \mathrm{~mm}$ in depth, first with bone removal, followed by compaction (densification) and then by no changes. This was consistent with DVC findings, 
where high localised accumulated compressive strains $(-80,000 \mu \varepsilon$ to $-100,000 \mu \varepsilon$ ) beyond the yield strain of bone were apparent at the surface of the condyles within the first $2.6 \mathrm{~mm}$, and decreased rapidly with increasing posterior-anterior depth. The combination of high-resolution 3D imaging and DVC provides important insight into the extent of plastic deformation of bone occurring due to femoral press-fit implantation. This data and the methods described can be used to inform surgeons and manufacturers, to compare bone response to different implant surface coating or press-fit values, advance computational models and implant development in future.

\section{Authors contribution statement}

SR and EP contributed to study design, data acquisition, analysis, interpretation and drafted the manuscript. SB and DJ contributed to study design, data acquisition, interpretation and critical revision of this manuscript. CEW and JPWB contributed to data acquisition and critical revision of this manuscript. GT and KJR contributed to the data interpretation and critical revision of this manuscript. All authors have read and approved the final submitted manuscript.

\section{Conflicts of interest}

The authors have no conflict of interest to declare.

\section{Acknowledgements}

This study was partially funded by a research grant by DePuy Synthes Joint Reconstruction (Leeds, UK). The funding body had no role in the study design, collection, analysis and interpretation of data, writing and decision to submit this article for publication. The authors would like to thank orthopaedic surgeon, Dr. S. van de Groes, for performing the press-fit implantations.

\section{Appendix A. Supplementary data}

Supplementary data to this article can be found online at https:// doi.org/10.1016/j.jmbbm.2019.04.054.

\section{References}

Apostu, D., Lucaciu, O., Berce, C., Lucaciu, D., Cosma, D., 2018. Current methods of preventing aseptic loosening and improving osseointegration of titanium implants in cementless total hip arthroplasty: a review. J. Int. Med. Res. 46, 2104-2119.

Basler, S.E., Mueller, T.L., Christen, D., Wirth, A.J., Muller, R., van Lenthe, G.H., 2011. Towards validation of computational analyses of peri-implant displacements by means of experimentally obtained displacement maps. Comput. Methods Biomech. Biomed. Eng. 14, 165-174.

Bay, B.K., Smith, T.S., Fyhrie, D.P., Saad, M., 1999. Digital volume correlation: threedimensional strain mapping using X-ray tomography. Exp. Mech. 39, 217-226.

Bayraktar, H.H., Morgan, E.F., Niebur, G.L., Morris, G.E., Wong, E.K., Keaveny, T.M., 2004. Comparison of the elastic and yield properties of human femoral trabecular and cortical bone tissue. J. Biomech. 37, 27-35.

Berahmani, S., Hendriks, M., de Jong JJA, van den Bergh JPW, Maal, T., Janssen, D., Verdonschot, N., 2018. Evaluation of interference fit and bone damage of an uncemented femoral knee implant. Clin. Biomech. 51, 1-9.

Bishop, N.E., Hohn, J.C., Rothstock, S., Damm, N.B., Morlock, M.M., 2014. The influence of bone damage on press-fit mechanics. J. Biomech. 47, 1472-1478.

Bosshardt, D.D., Salvi, G.E., Huynh-Ba, G., Ivanovski, S., Donos, N., Lang, N.P., 2011. The role of bone debris in early healing adjacent to hydrophilic and hydrophobic implant surfaces in man. Clin. Oral Implant. Res. 22, 357-364.

Curtis, M.J., Jinnah, R.H., Wilson, V.D., Hungerford, D.S., 1992. The initial stability of uncemented acetabular components. J. Bone Joint Surg. British 74, 372-376.

Damm, N.B., Morlock, M.M., Bishop, N.E., 2017. Influence of trabecular bone quality and implantation direction on press-fit mechanics. J. Orthop. Res. : Off. Publ. Orthop. Res. Soc. 35, 224-233.

Du, J., Lee, J.H., Jang, A.T., Gu, A., Hossaini-Zadeh, M., Prevost, R., Curtis, D. A., Ho, S.P. 2015. Biomechanics and strain mapping in bone as related to immediately-loaded dental implants. J. Biomech. 48, 3486-3494.
Gillard, F., Boardman, R., Mavrogordato, M., Hollis, D., Sinclair, I., Pierron, F., Browne, M., 2014. The application of digital volume correlation (DVC) to study the microstructural behaviour of trabecular bone during compression. J. Mech. Behav. Biomed. Mater. 29, 480-499.

Graves, S., Turner, C., 2018. National Joint Replacement Registry - Annual Report 2018. (Adelaide, Australia).

Green, J.R., Nemzek, J.A., Arnoczky, S.P., Johnson, L.L., Balas, M.S., 1999. The effect of bone compaction on early fixation of porous-coated implants. J. Arthroplast. 14, 91-97.

Hungerford, D.S., 1991. The technique of cementless total knee replacement. Tech. Orthop. 6, 1-7.

Hussein, A.I., Barbone, P.E., Morgan, E.F., 2012. Digital volume correlation for study of the mechanics of whole bones. Procedia IUTAM 4, 116-125.

Jemat, A., Ghazali, M.J., Razali, M., Otsuka, Y., 2015. Surface modifications and their effects on titanium dental implants. BioMed Res. Int. 2015, 791725.

Kienapfel, H., Sprey, C., Wilke, A., Griss, P., 1999. Implant fixation by bone ingrowth. J. Arthroplast. 14, 355-368.

Kold, S., Rahbek, O., Vestermark, M., Overgaard, S., Søballe, K., 2005. Bone compaction enhances fixation of weightbearing titanium implants. Clin. Orthop. Relat. Res. 431, $138-144$.

Kroker, A., Zhu, Y., Manske, S.L., Barber, R., Mohtadi, N., Boyd, S.K., 2017. Quantitative in vivo assessment of bone microarchitecture in the human knee using HR-pQCT. Bone 97, 43-48.

Liu, L., Morgan, E.F., 2007. Accuracy and precision of digital volume correlation in quantifying displacements and strains in trabecular bone. J. Biomech. 40, 3516-3520.

Martelli, S., Perilli, E., 2018. Time-elapsed synchrotron-light microstructural imaging of femoral neck fracture. J. Mech. Behav. Biomed. Mater. 84, 265-272.

Morgan, E.F., Keaveny, T.M., 2001. Dependence of yield strain of human trabecular bone on anatomic site. J. Biomech. 34, 569-577.

NJR Editorial Board, 2018. National Joint Registry for England, Wales, Northern Ireland and the Isle of Man: 15th Annual Report 2018.

Palanca, M., Tozzi, G., Cristofolini, L., Viceconti, M., Dall'Ara, E., 2015. ThreeDimensional local measurements of bone strain and displacement: comparison of three digital volume correlation approaches. J. Biomech. Eng. 137 071006-071006071014.

Perilli, E., Baleani, M., Ohman, C., Baruffaldi, F., Viceconti, M., 2007a. Structural parameters and mechanical strength of cancellous bone in the femoral head in osteoarthritis do not depend on age. Bone 41, 760-768.

Perilli, E., Baruffaldi, F., Visentin, M., Bordini, B., Traina, F., Cappello, A., Viceconti, M., 2007b. MicroCT examination of human bone specimens: effects of poly-

methylmethacrylate embedding on structural parameters. J. Microsc. 225, 192-200.

Perilli, E., Parkinson, I.H., Reynolds, K.J., 2012. Micro-CT examination of human bone: from biopsies towards the entire organ. Annali dell'Istituto superiore di sanita 48, $75-82$.

Pilliar, R.M., Lee, J.M., Maniatopoulos, C., 1986. Observations on the effect of movement on bone ingrowth into porous-surfaced implants. Clin. Orthop. Relat. Res. 108-113.

Press, W.H., Teukolsky, S.A., Vetterling, W.T., Flannery, B.P., 1992. Numerical Recipes in $\mathrm{C}++$. The Art of Scientific Computing.

Roberts, B.C., Perilli, E., Reynolds, K.J., 2014. Application of the digital volume correlation technique for the measurement of displacement and strain fields in bone: a literature review. J. Biomech. 47, 923-934.

Roberts, B.C., Thewlis, D., Solomon, L.B., Mercer, G., Reynolds, K.J., Perilli, E., 2017. Systematic mapping of the subchondral bone 3D microarchitecture in the human tibial plateau: variations with joint alignment. J. Orthop. Res. : Off. Publ. Orthop. Res. Soc. 35, 1927-1941.

Robertsson, O., Lidgren, L., Sundberg, M., W-Dahl A, 2017. Swedish Knee Arthroplasty Register - Annual Report 2017. Department of Clinical Sciences, Lund Sweden (Orthopedics).

Sukjamsri, C., Geraldes, D.M., Gregory, T., Ahmed, F., Hollis, D., Schenk, S., Amis, A., Emery, R., Hansen, U., 2015. Digital volume correlation and micro-CT: an in-vitro technique for measuring full-field interface micromotion around polyethylene implants. J. Biomech. 48, 3447-3454.

Tabassum, A., Walboomers, F., Wolke, J.G., Meijer, G.J., Jansen, J.A., 2011. The influence of surface roughness on the displacement of osteogenic bone particles during placement of titanium screw-type implants. Clin. Implant Dent. Relat. Res. 13, 269-278.

Taylor, M., Tanner, K.E., Freeman, M.A., 1998. Finite element analysis of the implanted proximal tibia: a relationship between the initial cancellous bone stresses and implant migration. J. Biomech. 31, 303-310.

Tozzi, G., Danesi, V., Palanca, M., Cristofolini, L., 2016. Elastic full-field strain analysis and microdamage progression in the vertebral body from digital volume correlation. Strain 52, 446-455.

Tozzi, G., Dall'Ara, E., Palanca, M., Curto, M., Innocente, F., Cristofolini, L., 2017. Strain uncertainties from two digital volume correlation approaches in prophylactically augmented vertebrae: local analysis on bone and cement-bone microstructures. J. Mech. Behav. Biomed. Mater. 67, 117-126.

Zhu, M.L., Zhang, Q.H., Lupton, C., Tong, J., 2016. Spatial resolution and measurement uncertainty of strains in bone and bone-cement interface using digital volume correlation. J. Mech. Behav. Biomed. Mater. 57, 269-279. 